\title{
Polymers Based on Methacrylate Bearing Coumarin Side Group: Synthesis via Free Radical Polymerization, Monomer Reactivity Ratios, Dielectric Behavior, and Thermal Stabilities
}

\author{
Nursel Ayaz, ${ }^{1}$ Feride Bezgin, ${ }^{2}$ and Kadir Demurellı ${ }^{1}$ \\ ${ }^{1}$ Department of Chemistry, Faculty of Science, University of Firat, 23119 Elazig, Turkey \\ ${ }^{2}$ Department of Chemistry, Faculty of Arts and Sciences, University of Bitlis Eren, 13000 Bitlis, Turkey \\ Correspondence should be addressed to Kadir Demırellı, kdemirelli@firat.edu.tr
}

Received 6 December 2011; Accepted 29 December 2011

Academic Editors: P. Dobrzynski, A. V. Popov, and I. Tomita

Copyright (C) 2012 Nursel Ayaz et al. This is an open access article distributed under the Creative Commons Attribution License, which permits unrestricted use, distribution, and reproduction in any medium, provided the original work is properly cited.

\begin{abstract}
Copolymerization and homopolymerization of 7-methacryloyloxy coumarin (MAOC) and its copolymers with benzyl methacrylate (BMA), methyl methacrylate (MMA), ethyl methacrylate (EMA), and isobuthyl methacrylate (IBMA) were performed by the free radical polymerization method (FRP) at low conversions $(<15 \%)$. The resulting polymers were characterized by FTIR, ${ }^{1} \mathrm{H}$ NMR, GPC, DSC, and TGA. The monomer reactivity ratios of MAOC and BMA were computed using Kelen-Tüdös (K-T) and Fineman-Ross (F-R) methods and were found to be $r_{1}=0.45, r_{2}=1.29 ; r_{1}=0.46 ; r_{2}=1.33$, respectively $\left(r_{1}\right.$ is monomer reactivity ratio of MAOC). Blends of poly(MAOC) and poly(BMA) obtained via FRP method were prepared by casting films from dichloromethane solution and were characterized by DTA and TGA techniques. Dielectric measurements for MAOC homopolymer and its copolymers with EMA, MMA, and IBMA were carried out by means of an impedance analyzer as a function of temperature and frequence. Dielectric properties of polymer samples prepared in a plate form were measured at room temperature over the frequency range $0.1 \mathrm{kHz}-2 \mathrm{MHz}$ and given as compared with each other.
\end{abstract}

\section{Introduction}

Coumarin-containing polymers have been well studied and widely applied in many fields, such as biochemicals, electrooptical materials, organic-inorganic hybrid materials, liquid crystalline materials, and light-harvesting/energy-transferring materials [1-3]. However, most reported coumarincontaining polymers were linear polymers [4]. And the coumarin functional group was introduced as a pendent group or terminal group of the polymer chain [5-7]. The chemical modification of coumarins allows us to vary emission wavelength continuously throughout the visible spectrum [8]. Photopolymers are studied for their macromolecular properties and for the properties of the photosensitive group. Among them, polymers having photocrosslinkable functional groups, such as cinnamoyl, chalcone, thymine, or coumarin, represent an active field of research in polymer science because of their technological applications in the fields of photolithography [9], nonlinear optical materials
[10], liquid crystalline materials [11], and holographic elements [12]. 7-hydroxycoumarin is a widely used structure in introducing the coumarin unit into polymer [13, 14]. These polymers are known as "light harvesting" or "antenna" polymers and commonly involve vinyl aromatic polymers with pendant chromophores capable of efficient light collection and long-range energy transfer.

The copolymer composition and comonomers units distribution depend on monomer reactivity ratios. The most common mathematical model of copolymerization is based on finding the relationship between the composition of copolymers and the composition of the monomer feed in which the monomer-reactivity ratios are the parameters to be determined [15]. The calculation of the monomer-reactivity ratios requires the mathematical treatment of experimental data on the composition of copolymers and monomer in feed mixtures. The most fundamental quantities characterizing a copolymer is its composition on a molar basis, which eventually is used for the determination of the relevant 
monomer reactivity ratios. Spectroscopic methods, preferably ${ }^{1} \mathrm{H}-\mathrm{NMR}$ spectroscopy $[16,17]$, and elemental analysis are probably the most widely used methods for the analysis of copolymers and the determination of reactivity ratios $r_{1}$ and $r_{2}$.

At low frequencies, thermal characteristics of dielectric constant of the composites strongly depend on both the polymer polarity and flexibility. The composites based on a nonpolar polymer matrix show little variation of their dielectric constant with temperature. On the other hand, the dielectric constant of the composites based on a polar polymer matrix strongly depends on the polymer state. At the temperatures where the polymer matrix is in its glassy state, the dielectric constant is much lower than that in the elastic state with a steep increase around the glass transition temperature [16].

The objective of the present work is to investigate the polymer properties of 7-methacryloyloxy coumarin having a bulky side chain onto coumarine. In this work, two different copolymer systems were prepared. One of them is MAOC/MMA, EMA, IBMA copolymer system, the other is six MAOC-BMA copolymer system. Thus, this paper describes synthesis of polymers prepared by free radical homo- and copolymerization of BMA, MMA, EMA, IBMA with 7-methacryloyloxy coumarin iniated with AIBN, the dielectric behavior by depending upon frequence and temperature of MAOC/MMA, EMA, IBMA copolymer series, to determine monomer reactivity ratios of MAOC-BMA copolymer series, and characterization of the homo- and copolymers with FTIR, ${ }^{1} \mathrm{H},{ }^{13} \mathrm{C}-\mathrm{NMR}$, thermal analysis, gel permeation chromatography (GPC), and impedance analysis.

\section{Experimental}

2.1. Materials. 7-hydroxycoumarin was purchased from Sigma-Aldrich and used as received. Isobutyl methyacrylate (IBMA), methyl methacrylate, ethyl methacrylate (EMA) (Aldrich) were distilled under vacuum before use. 2,2' Azobisisobutyronitrile (AIBN), methacryloyl chloride, tetrahydrofuran (THF), and ethanol (Fluka) were used without further purification.

2.2. Measurements. ${ }^{1} \mathrm{H}$ NMR spectra were obtained on a AVANCE III $400 \mathrm{MHz}$ Bruker, using $\mathrm{CDCl}_{3}$ as the solvent and tetramethylsilane as an internal standard. Infrared spectra were recorded on a Perkin-Elmer Spectrum One FTIR spectrometer. Calorimetric measurements were carried out on a Shimadzu DSC-50 thermal analyzer under $\mathrm{N}_{2}$ flow a using a heating rate of $20^{\circ} \mathrm{C} / \mathrm{min}$. Experiments were carried out on approximately $3-5 \mathrm{mg}$ samples at a heating rate of $10^{\circ} \mathrm{C} \mathrm{min^{-1 }}$ under nitrogen flow conditions $\left(10 \mathrm{~cm}^{3} \mathrm{~min}^{-1}\right)$. The molecular weight and molecular weight distribution were determined using an Agilent 1100 gel permeation chromatography (GPC) system equipped with a Waters Styragel column, a refractive index detector, and a pump. The column was calibrated with polystyrene, and samples were eluted using THF. The polymer was ground with an agate mortar and pestle, and the final fine powder was pressed at four tons of pressure into disk-shaped samples with a thickness ranging from $0.94 \mathrm{~mm}$ to $2.22 \mathrm{~mm}$ and a diameter of $12 \mathrm{~mm}$. The entire surface of the discs was coated with silver paste, which acts as a good contact for capacitance measurements. The capacitance measurements were carried out at room temperature with a QuadTech 7600 precision LRC Meter impedance analyzer over the frequency range $1 \mathrm{kHz}-2 \mathrm{MHz}$.

2.3. Synthesis of 7-methacryloyloxy Coumarin (MAOC). The synthesis of 7-methacryloyloxy coumarin (MAOC) monomer carried out according to the usual method [17]. The product was recrystallized from ethanol ( $\mathrm{mp}$ measured by DSC: $\left.105^{\circ} \mathrm{C}\right)$.

IR $\left(\mathrm{KBr}\right.$, thin film, $\left.\mathrm{cm}^{-1}\right): 3073(-\mathrm{CH}$ stretching of the aromatic ring), $2986\left(-\mathrm{CH}_{3}\right), 1737$ (broad, $\mathrm{C}=\mathrm{O}$ in ester), $1630(\mathrm{C}=\mathrm{C}), 1230$ (asymmetric $\mathrm{C}-\mathrm{O}-\mathrm{C}$ ), and 1142 (symmetric $\mathrm{C}-\mathrm{O}-\mathrm{C})$.

${ }^{1} \mathrm{H} \mathrm{NMR}\left(\delta \mathrm{ppm}, \mathrm{CDCl}_{3}\right): 2.08\left(\mathrm{~s}, 3 \mathrm{H}, \mathrm{CH}_{3}\right), 5.84(\mathrm{~s}, 1 \mathrm{H}$, $\mathrm{CH}=), 6.40(\mathrm{~s}, 1 \mathrm{H}, \mathrm{CH}=), 7.02-7.74(4 \mathrm{H}$, on coumarin ring), and $6,38(\mathrm{~s}, 1 \mathrm{H},=\mathrm{CH}$ next to $\mathrm{C}=\mathrm{O}$ on coumarin group).

2.4. Synthesis of Benzyl Methacrylate (BMA). BMA was synthesized by reaction benzylalcohol with methacryloyl chloride in presence of triethyl amine at $0-5^{\circ} \mathrm{C}$.

IR $\left(\mathrm{cm}^{-1}\right.$, the most characteristic bands): $1738(\mathrm{C}=\mathrm{O}$ stretching), 1638 ( $\mathrm{C}=\mathrm{C}$ in the vinyl group), and $1600(\mathrm{C}=\mathrm{C}$ stretch in aromatic ring).

${ }^{13} \mathrm{C} \mathrm{NMR}\left(\mathrm{CDCI}_{3}, \delta_{\mathrm{ppm}}\right): 17.7\left(\mathrm{CH}_{3}\right), 65.7\left(-\mathrm{OCH}_{2}-\right)$, 135.9 (ipso carbon on aromatic ring), 124.8-128.0 (CH on aromatic ring), and $136.8(=\mathrm{C}), 166.0(\mathrm{C}=\mathrm{O})$.

${ }^{1} \mathrm{H}-\mathrm{NMR}\left(\mathrm{CDCI}_{3}, \delta_{\mathrm{ppm}}\right): 1.96(\mathrm{~s}, 3 \mathrm{H}), 5.3(\mathrm{~s}, 2 \mathrm{H}), 5.6(\mathrm{~s}$, $1 \mathrm{H}), 6.2(\mathrm{~s}, 1 \mathrm{H})$, and $7.3(5 \mathrm{H})$.

2.5. Free Radical Polymerization of MAOC. MAOC was recrycstallized within ethylalcohol. monomer was polymerized at $60^{\circ} \mathrm{C}$ in 1,4-dioxane in the presence of AIBN as an initiator. The poly(MAOC) was purified by precipitation in petroleum ether. This process was repeated twice. The polymer was then dried at $40^{\circ} \mathrm{C}$ for $24 \mathrm{~h}$.

2.6. Free Radical Copolymerization of MAOC with BMA, $M M A, E M A$, and IBMA. First, six copolymers of MAOC with BMA were prepared in 1,4-dioxane at $60^{\circ} \mathrm{C}$ in the presence of AIBN. Predetermined amounts of the monomers, AIBN, and the solvent were mixed in a polymerization tube. The mixture was degassed for about $10 \mathrm{~min}$ with argon and kept in a thermostated oil bath at $60^{\circ} \mathrm{C}$. After desired time the mixture was cooled to ambient temperature. The copolymers were precipitated into excess ethanol and purified by reprecipitation, and then the copolymers were dried at $40^{\circ} \mathrm{C}$ for $24 \mathrm{~h}$. Also, copolymers of MAOC with MMA, EMA, and IBMA was prepared under the same conditions. The copolymeric units of MAOC with MMA, EMA, and IBMA can be represented according to Scheme 1. 

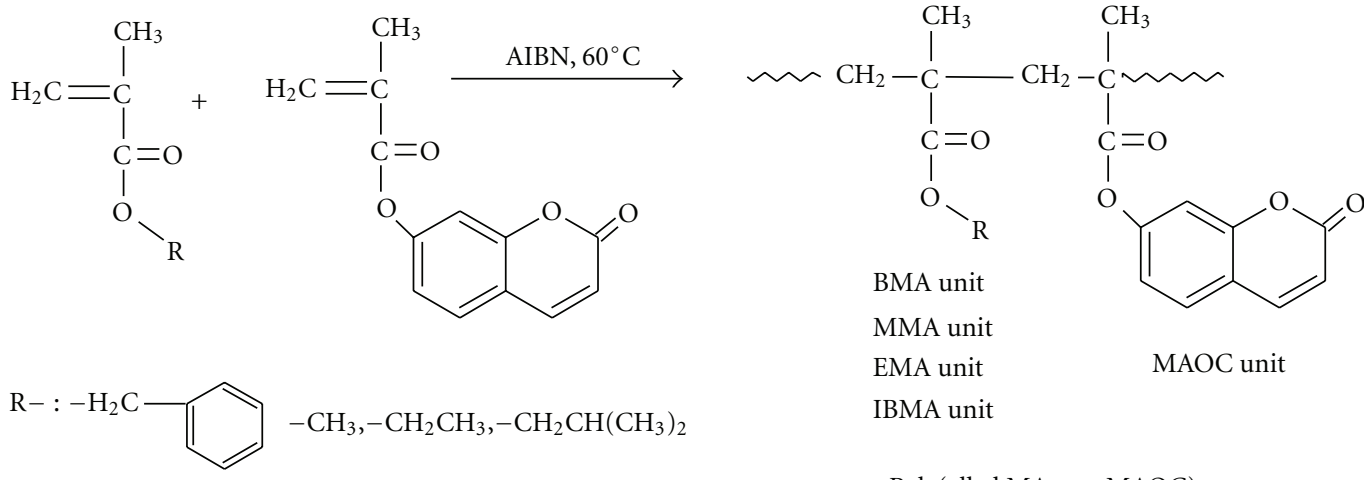

Poly(alkyl MA-ran-MAOC)

Scheme 1: The structure monomeric units of the copolymer.

2.7. Preparation of Polymer Blends. Poly(MAOC) and poly (BMA) blend samples were prepared by solution casting from dichloromethane at room temperature, and the blends were dried at room temperature in vacuo.

\section{Results and Discussion}

3.1. Characterization of Copolymers. The ${ }^{1} \mathrm{H}$ NMR spectra of poly(MAOC), poly(BMA), and MAOC-BMA copolymers prepared via free radical polymerization (FRP) are shown in Figure 1. The peaks at $6.36-7.3 \mathrm{ppm}$ reveal the coumarin ring protons, and the signal at $4.91 \mathrm{ppm}$ is assigned to methylene adjacent to ester oxygen in BMA units. As the MAOC units in copolymer increases from 19 to $84 \mathrm{~mol} \%$, the intensity of $=\mathrm{CHC}=\mathrm{O}$ protons in MAOC units gradually increases. The other signals, $1.1-2.2 \mathrm{ppm}$, are due to the methyl and methylene protons of the main backbone in MAOC and BMA units. The ${ }^{13} \mathrm{C}$ NMR spectrum illustrated in Figure 2 of the copolymer (with 58 mol \% MAOC units) has the most characteristic peaks of the monomeric units at $177.2 \mathrm{ppm}(\mathrm{C}=\mathrm{O}$ in BMA units), $176.9 \mathrm{ppm}(\mathrm{C}=\mathrm{O}$ in $\mathrm{MOC}$ units), $160.0 \mathrm{ppm}$ ( $\mathrm{C}=\mathrm{O}$ on coumarin ring in MAOC units), $80.95 \mathrm{ppm}\left(-\mathrm{OCH}_{2}-\mathrm{Ar}\right.$ ), 54 and $52.78 \mathrm{ppm}$ (quaternary carbons of BMA and MAOC in both units, resp.), and 160,0 ppm ( $\mathrm{C}=\mathrm{O}$ on coumarin ring).

${ }^{1} \mathrm{H}$ NMR spectra of poly(MAOC-co-MMA 0,19), poly (MAOC-co-EMA 0,19), and poly(MAOC-co-IBMA 0,23) showed important signals at $6.25-7.80 \mathrm{ppm}$ (aromatic protons), and signals at $3.66 \mathrm{ppm}\left(2 \mathrm{H},-\mathrm{OCH}_{3}\right.$ in $\mathrm{MMA}$ unit), $4.06 \mathrm{ppm}\left(2 \mathrm{H},-\mathrm{OCH}_{2}\right.$ in EMA unit), and $3.72 \mathrm{ppm}(3 \mathrm{H},-$ $\left.\mathrm{OCH}_{2} \mathrm{CH}\left(\mathrm{CH}_{3}\right)_{2}\right)$ in IBMA unit).

The IR spectra of the resulting copolymers with various feed ratios of MAOC and BMA prepared by free radical copolymerization showed the absorbance at 737 and $697 \mathrm{~cm}^{-1}$, which is attributed to a vibration characteristic of a monosubstituted benzene ring in BMA moieties. The stretchs at 737 and $697 \mathrm{~cm}^{-1}$, whose relative intensities gradually increase as the percentage of BMA in the copolymers increases from 16 to 81 mole \% (or from 19 to $84 \%$ in view of MAOC unit). The peak at $1731 \mathrm{~cm}^{-1}$ is assigned to the vibration of ester carbonyl in MAOC and BMA units. IR spectra of copolymers of MAOC with MMA, EMA, and IBMA are similar to each other. But that of poly(MAOC-co-IBMA) is as a significant different for $\mathrm{C}-\mathrm{H}$ vibration of isobuthyl group at $1470-1360 \mathrm{~cm}^{-1}$. Figure 3 shows the UV-vis spectra of polymer, both the homopolymer and the copolymer had a strong UV-vis absorption at $322 \mathrm{~nm}$. However, the weaker $\mathrm{UV}$-vis absorption intensities of the polymer from $268 \mathrm{~nm}$ to $300 \mathrm{~nm}$ wavelength could be attributed to the disappearance of intermolecular or intramolecular exciplex between the electron-donating chromophore and the electron-deficient metacrylic carbon-carbon double bonds [18].

The monomer feed ratio and the $M n$ and $M w / M n$ for poly(MAOC) and its copolymers with MMA, EMA, and IBMA are listed in Table 1. The monomer feed ratio and the $M n$ and $M w / M n$ of six copolymer for MAOC-BMA copolymer system are listed in Table 2. In MAOC-BMA copolymer system, it increases in $M n$ values with an increasing molar fraction of BMA in the copolymer. This therefore indicates that the decreasing average molecular weight of the copolymer can be manipulated by the controlled polymerization conversion of BMA units. The resulting copolymers possess relatively narrow polydispersities (1.1 $<M w / M n<1.27)$. This suggests that the contribution of chain breaking and transfer as well as termination reactions during copolymerization can be neglected until a higher polymerization conversion, which is similar to the result reported by Popielarz et al. [19].

3.2. Determination of Copolymer Composition by ${ }^{1} \mathrm{H} N \mathrm{NR}$. The ${ }^{1} \mathrm{H}$ NMR technique is well established as a simple rapid, and accurate method for the determination of copolymer composition $[16,17]$. The assignment of the resonance peaks in ${ }^{1} \mathrm{H}$ NMR spectrum allows for the accurate evaluation of the content of each kind of monomeric unit incorporated into the copolymer chain. Thus, the mole fraction of MAOC in the copolymer chains was calculated from integrated intensities of aromatic protons of MAOC and aliphatic protons of MMA, EMA, and IBMA units. The following expression applies to copolymers. Let $m_{1}$ be the mole fraction of MAOC and $1-m_{1}$ that of MMA, EMA, and IBMA. There are one olephinic proton the neighboring to carbonyl in MAOC unit and, protons which are adjacent to ester oxygen in MMA, EMA and IBMA units. Table 1 gives the value of 


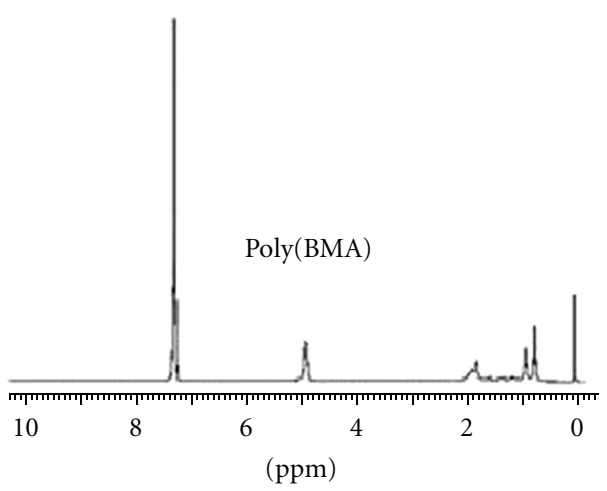

(a)

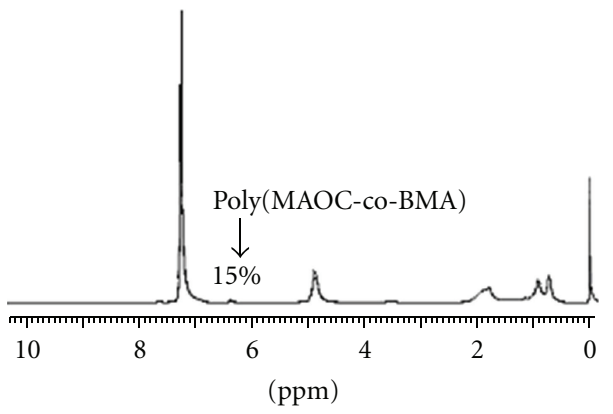

(c)

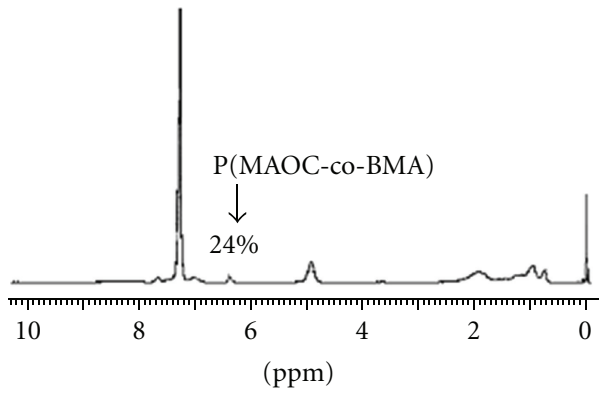

(e)

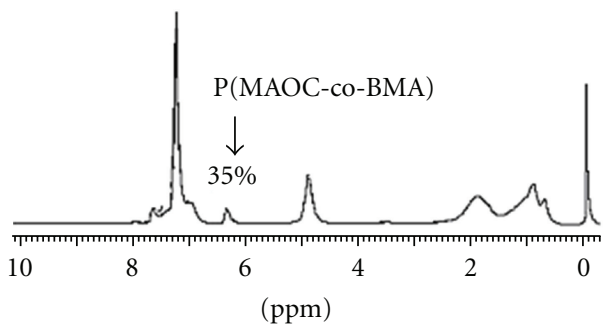

(g)

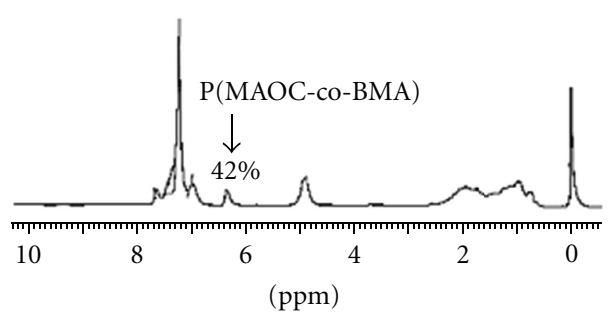

(b)

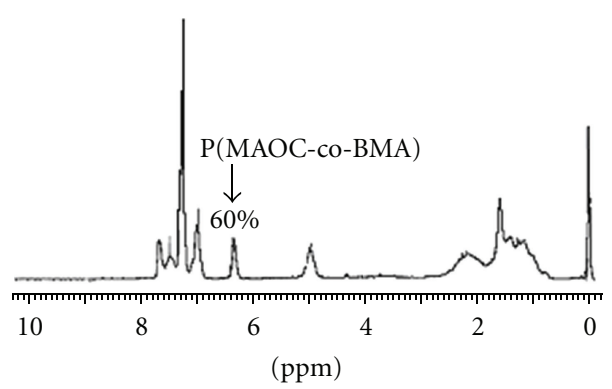

(d)

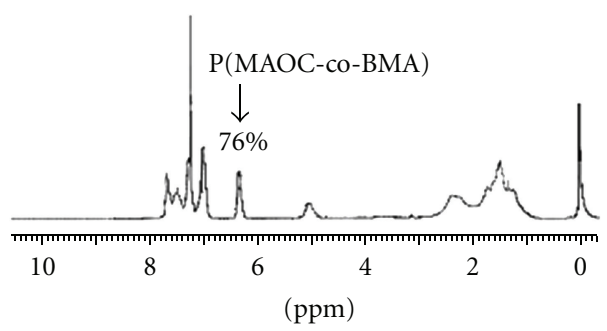

(f)

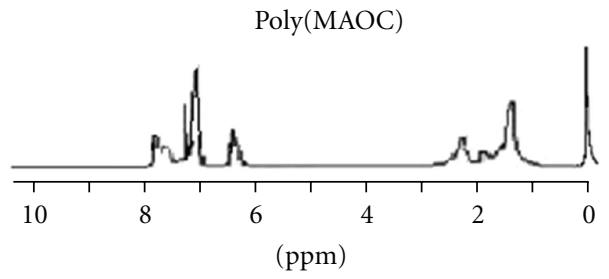

(h)

Figure 1: ${ }^{1} \mathrm{H}$ NMR spectra of poly(MAOC), poly(BMA) and six copolymer compositions.

mole fraction of MAOC on the copolymers. All copolymer samples exhibited higher concentrations of MMA, EMA, and IBMA units.

3.3. Monomer Reactivity Ratios. The free radical copolymerization of MAOC and BMA initiated AIBN for various ratios of MAOC and BMA has been carried out $60^{\circ} \mathrm{C}$. Table 1 shows the influence of the initial molar compositions of the comonomers on those of the comonomers in the copolymers, for free radical copolymerization. Knowledge of the copolymer composition is an important step in the evaluation of its utility. The copolymer composition and its distribution depend on monomer reactivity ratios. The copolymer compositions to determine monomer reactivity ratios were analyzed by ${ }^{1} \mathrm{NMR}$ spectra. Figure 1 shows ${ }^{1} \mathrm{H}$ NMR spectra of the copolymer prepared by FRP. The peaks 


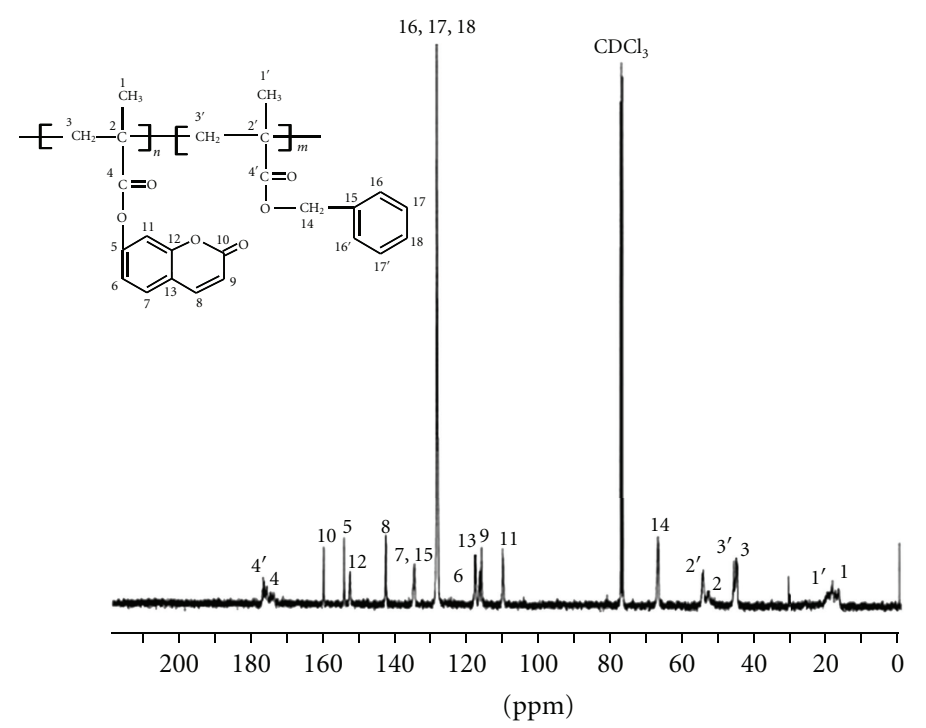

Figure 2: ${ }^{13} \mathrm{C}$ NMR spectrum of poly(MAOC:BMA) (42:58 mol \%).

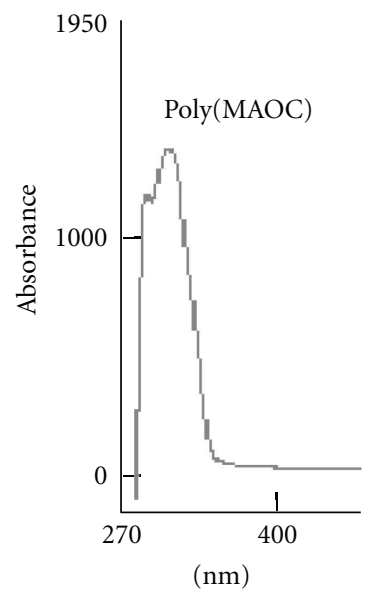

(a)

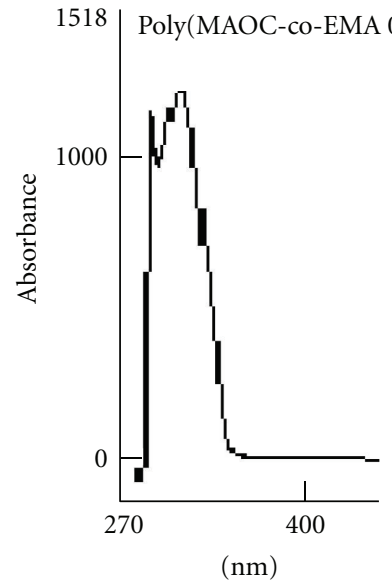

(c)

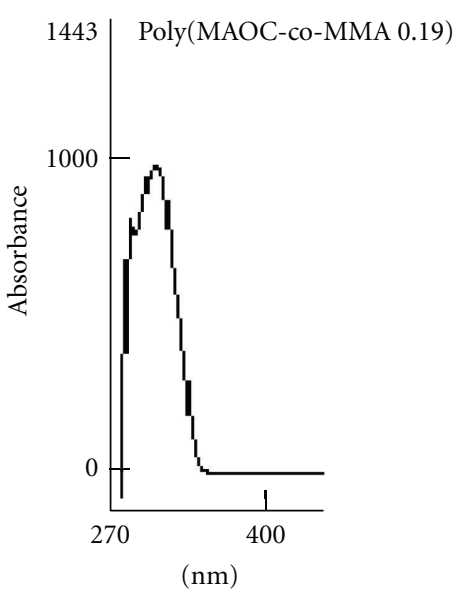

(b)

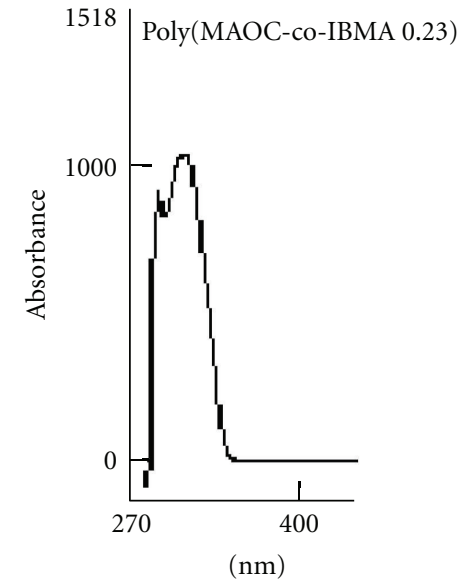

(d)

Figure 3: Absorption spectra of poly(MAOC) and some copolymers in THF at $10^{-5} \mathrm{moldm}^{-3}$. 
TABLE 1: Initial and experimental data of MAOC in copolymer compositions.

\begin{tabular}{lccccc}
\hline Copolymers & $M_{1}^{\mathrm{a}}$ & Intensity of aromatic protons & Intensities of aliphatic protons & $m_{1}^{\mathrm{b}}$ & $\mathrm{Mn}(\mathrm{MwMn}) \mathrm{GPC}$ \\
\hline Poly(MAOC-co-MMA) & 0.25 & 0.20 & 1.67 & 0.19 & $31.000(1.56)$ \\
Poly(MAOC-co-EMA) & 0.23 & 0.15 & 1.84 & 0.19 & $20.300(1.68)$ \\
Poly(MAOC-co-IBMA) & 0.30 & 0.18 & 1.20 & 0.23 & $28.800(1.81)$ \\
\hline
\end{tabular}

a: Initial mole fraction of MAOC in feed.

b: Mole fraction of MAOC in copolymers.

TABLE 2: Copolymerization of MAOC and BMA at various monomer feeds ${ }^{\mathrm{a}}$ and copolymer characteristics.

\begin{tabular}{cccccc}
\hline Sample & $M_{1}^{\mathrm{b}}$ & $\begin{array}{c}\text { Intensity of } \\
=\mathrm{CHC}=\mathrm{O} \text { proton } \\
\text { in MAOC Unit }\end{array}$ & $\begin{array}{c}\text { Intensity of } \\
-\mathrm{OCH}_{2} \text { - protons } \\
\text { in BMA Unit }\end{array}$ & $m_{1}^{\mathrm{c}}$ & $\begin{array}{c}M n(M w / M n) \\
(\mathrm{GPC})\end{array}$ \\
\hline 1 & 0.19 & 0.90 & 10 & 0.15 & $5000(1.20)$ \\
2 & 0.37 & 1.55 & 10 & 0.24 & $4000(1.15)$ \\
3 & 0.44 & 2.60 & 10 & 0.35 & $5300(1.22)$ \\
4 & 0.50 & 3.50 & 10 & 0.42 & $3800(1.27)$ \\
5 & 0.77 & 7.35 & 10 & 0.60 & $3900(1.25)$ \\
6 & 0.84 & 15.65 & 10 & 0.76 & $3800(1.11)$ \\
\hline
\end{tabular}

a: conditions of polymerization; FRP at $60^{\circ} \mathrm{C}$.

b: mole fraction of MAOC in feed.

c: mole fraction of MAOC in copolymer.

d: the copolymers were prepared at low conversions $(<15 \%)$.

at $6,36 \mathrm{ppm}$ correspond to the aromatic protons, which is next to $\mathrm{C}=\mathrm{O}$ on coumarin ring in MAOC units, the signal centered at $4.91 \mathrm{ppm}$ is assigned to methylene protons adjacent to oxygen in BMA units. The other signals at $1-2.2 \mathrm{ppm}$ are assigned to methylene and methyl in the polymer main chain for two units. Thus, the mole fractions of MAOC and BMA in the copolymer were determined from the ratio of the integral intensities of aromatic protons, which is next to $\mathrm{C}=\mathrm{O}$ on coumarin ring in MAOC units, $6,36(1 \mathrm{H}) \mathrm{ppm}$, and the methylene protons adjacent to oxygen at 4,91 ppm for BMA units. Copolymer compositions have been calculated from the following equation: integral intensities of aromatic protons $\left(I_{\mathrm{Ar}}\right)$, integral intensities of aliphatic protons $\left(I_{\text {Alp }}\right)$

$$
\begin{aligned}
\mathrm{C} & =\frac{\text { Integral values of }=\mathrm{CHC}=\mathrm{O} \text { protons on coumarin ring of MAOC unit }}{\text { Integral values of } \mathrm{OCH}_{2} \text { protons in BMA unit }} \\
& =\frac{m_{1}}{2 m_{2}} \quad \text { On simplification; } m_{1}=\frac{2 \mathrm{C}}{1+2 \mathrm{C}}
\end{aligned}
$$

where $m_{1}$ is mole fraction of MAOC and $m_{2}$ is that of BMA in copolymer. The $\mathrm{K}-\mathrm{T}$ and $\mathrm{F}-\mathrm{R}$ parameters were calculated, using data in Table 2, for free radical copolymerization of MAOC and BMA, and the results were summarized in Tables 3 and 4, respectively. It is well known that monomer reactivity ratios can be indicative of relative reactivity of comonomers $[20,21]$. To estimate the relative reactivity of MAOC and BMA in free radical copolymerization, the Yee et al. [22] and Tüdös and Kelen [23] equations were used, which are $\eta=\left(\left(r_{1}+r_{2}\right) / \alpha\right) \xi-r_{2} / \alpha$ and $G=r_{1} H-r_{2}$, respectively. (Notations in the equations are described in Tables 2 and 3.) The plots of $G$ versus $H$ and $\eta$ versus $\xi$ for copolymer system are shown in Figures 4(a) and 4(b), respectively. From the slope and intercept, the monomer reactivity ratios of MAOC and BMA were determined and found to be $r_{1}=0,45, r_{2}=1,29 ; r_{1}=0.46$; $r_{2}=1,33$, respectively $\left(r_{1}\right.$ is monomer reactivity ratio of MAOC). Monomer reactivity ratio of BMA is slightly higher than 1, and that of MAOC is importantly lesser than 1, for the copolymerization. $r_{1} \cdot r_{2}=0,58$. Apparently, the values of monomer reactivity ratios indicate that the growing radicals with BMA ends were added to MAOC or BMA monomers, but the radicals with BMA ends have a lesser tendency to be added to MAOC, in radical copolymerizations. The copolymerization system is more manipulated by BMA radicals. Distributions of the monomeric units along the copolymer chains are random, and they are slightly richer in BMA units. The microstructure of a polymeric material plays an important role in the behavior of the material toward a variety of biological systems and could be especially important in copolymerizations with monomers of different reactivities [24]. 


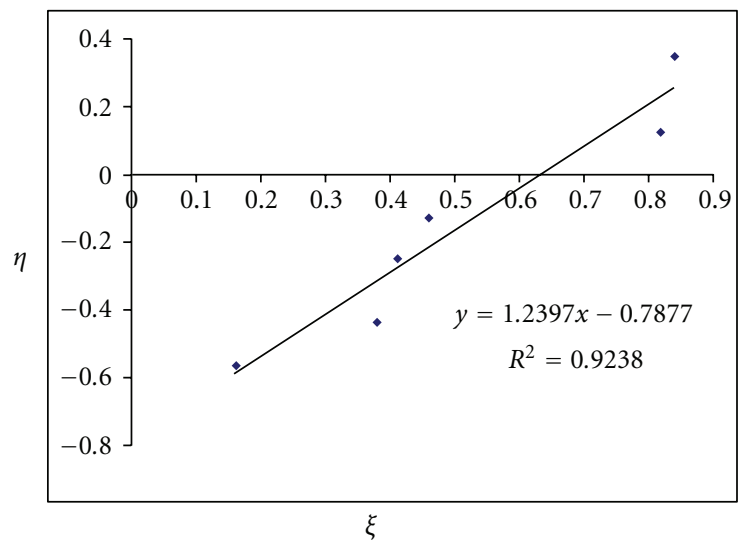

(a)

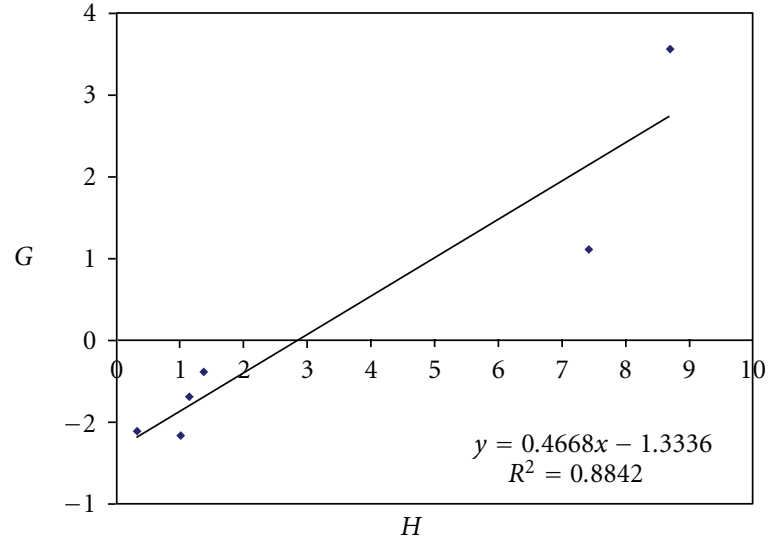

(b)

FIgURE 4: (a) Kelen-Tüdös and (b) Fineman-Ross plots for the free radical polymerization of MAOC and BMA.

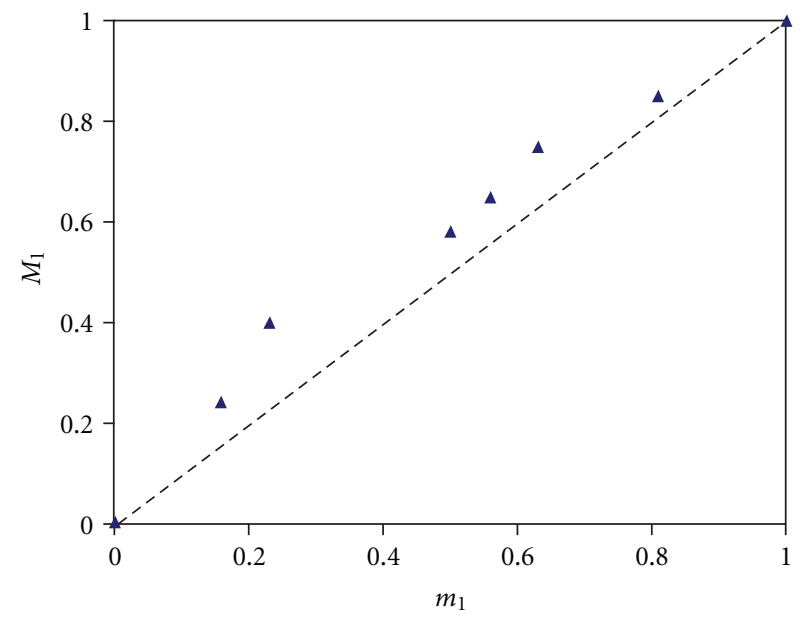

FIGURE 5: Composition diagrams of free radical copolymerization.

For the copolymerizations, the behaviors of the systems were evaluated through plots of the copolymer compositions $\left(m_{1}\right)$ measured from ${ }^{1} \mathrm{H}$ NMR as the molar fraction of MAOC versus the feed compositions is measured as the molar fraction of MAOC $\left(M_{1}\right)$ (Figure 5). It is seen that compositions of copolymer obtained from the copolymerization technique showed a positive deviation than linearly and did not show that they have an azeotropic composition. In normal free radical polymerization, continuous initiation leads to chain initiation and termination at different stages of the polymerization [25]. The values of $M w / M n$ in copolymerization are also known to depend on chain termination in the same way as in homopolymerization [4].

3.4. DSC Measurements. It is well recognised that intrinsic flexibility of polymeric chains is related to the glass transition temperature in amorphous macromolecules, with the measure of the $\mathrm{Tg}$ being a good way to know the

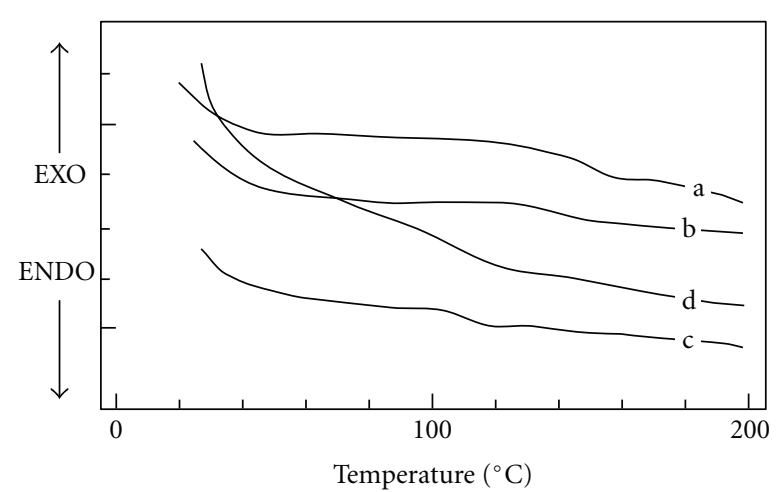

Figure 6: DSC traces of (a) poly(MAOC), (b) poly(MAOC-coMMA 0,19), (c) poly(MAOC-co-EMA 0,19), and (d) poly(MAOCCo-IBMA 0,23).

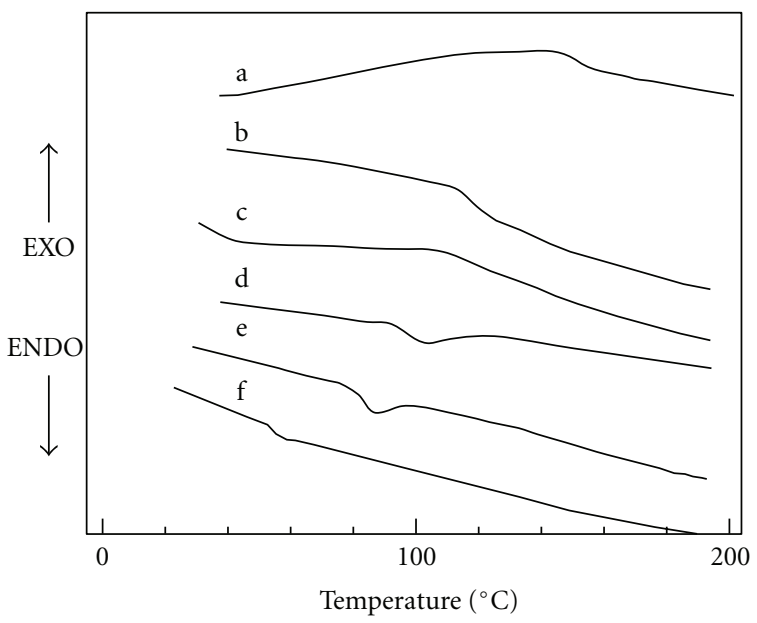

Figure 7: DSC curves of copolymer system: (a) poly(MAOC), (b) poly(MAOC 0,76-co-BMA), (c) poly(MAOC 0,60-co-BMA), (d) poly(MAOC 0,35-co-BMA), (e) poly(MAOC 0,15-co-BMA), and (f) poly(BMA) heated at $20^{\circ} \mathrm{C} / \mathrm{min}$ to $200^{\circ} \mathrm{C}$. 
TABLE 3: Results of the free radical copolymerization of MAOC and BMA.

\begin{tabular}{ccccccc}
\hline Deney & $F=M_{1} / M_{2}$ & $f=m_{1} / m_{2}$ & $G=F(f-1) / f$ & $H=F_{2} / f$ & $\eta=G /(\alpha+H)$ & $-0,57$ \\
\hline 1 & 0,23 & 0,17 & $-1,12$ & 0,31 & $-0,44$ & 0,16 \\
2 & 0,58 & 0,33 & $-1,17$ & 1,01 & $-0,25$ \\
3 & 0,78 & 0,53 & $-0,69$ & 1,14 & $-0,13$ & 0,38 \\
4 & 1,00 & 0,72 & $-0,38$ & 1,38 & 0,12 & 0,41 \\
5 & 3,34 & 1,50 & 1,11 & 7,43 & 0,46 \\
6 & 5,25 & 3,16 & 3,58 & 8,72 & 0,35 & 0,82 \\
\hline
\end{tabular}

$M_{1}$ : mole fraction of PMA in feed; $M_{2}$ : mole fraction of MMA in feed; $m_{1}$ : mole fraction of PMA in copolymer; $m_{2}$ : mole fraction of MMA in copolymer. $\left(H_{\min }, H_{\max }\right)^{1 / 2}=1,64 ; H_{\min }$ : lowest value of $H, H_{\max }$ : highest value of $H$.

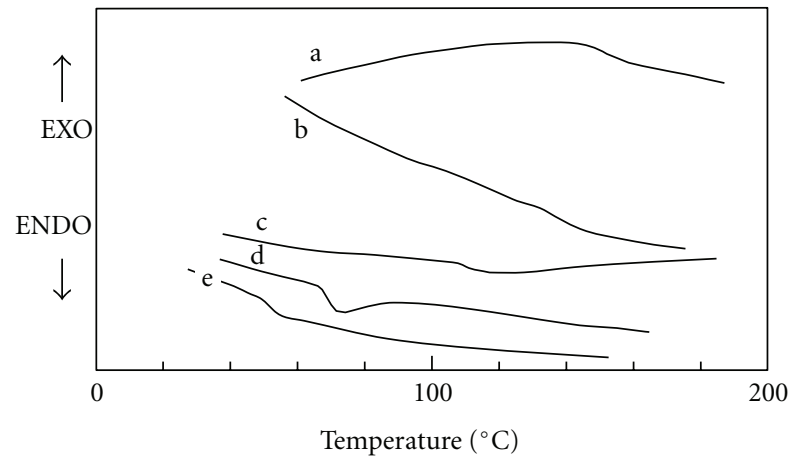

FIGURE 8: DSC curves of blend polymers: (a) poly(MAOC), (b) poly(MAOC)0,76-poly(BMA), (c) poly(MAOC)0,60-poly(BMA), (d) poly(MAOC)0,15-poly(BMA), and (e) poly(BMA) heated at $20^{\circ} \mathrm{C} / \mathrm{min}$ to $200^{\circ} \mathrm{C}$.

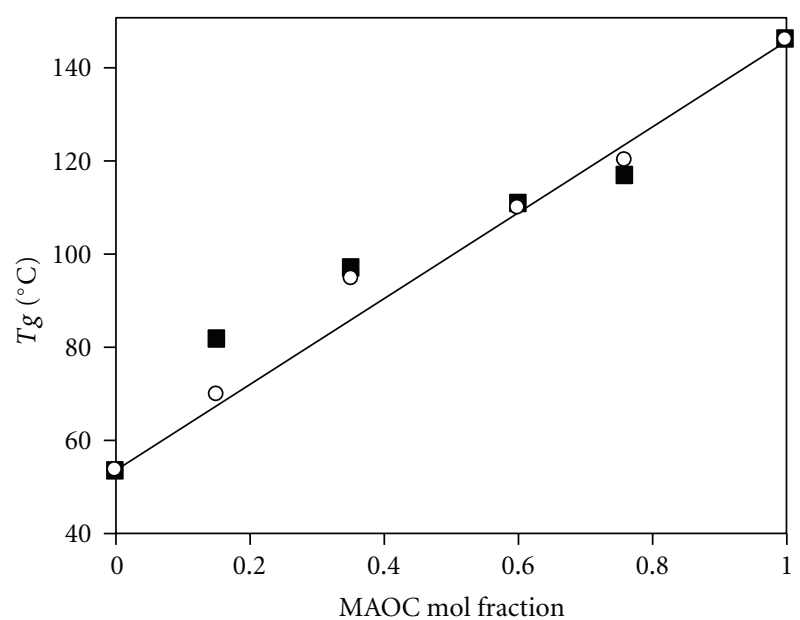

MAOC-BMA copolymer system

○ Poly(MAOC)-poly(BMA) blend system

FIgUre 9: Plots of the $\mathrm{Tg}$ of a series polymers as a function of $\mathrm{MAOC}$ in the blend and copolymer systems.

segmental mobility of polymer and copolymer chains of high molecular weight, in which the influence of chain ends is negligible [26]. The glass-transition temperatures $(\mathrm{Tg})$ of poly (MAOC) and all the copolymers were determined

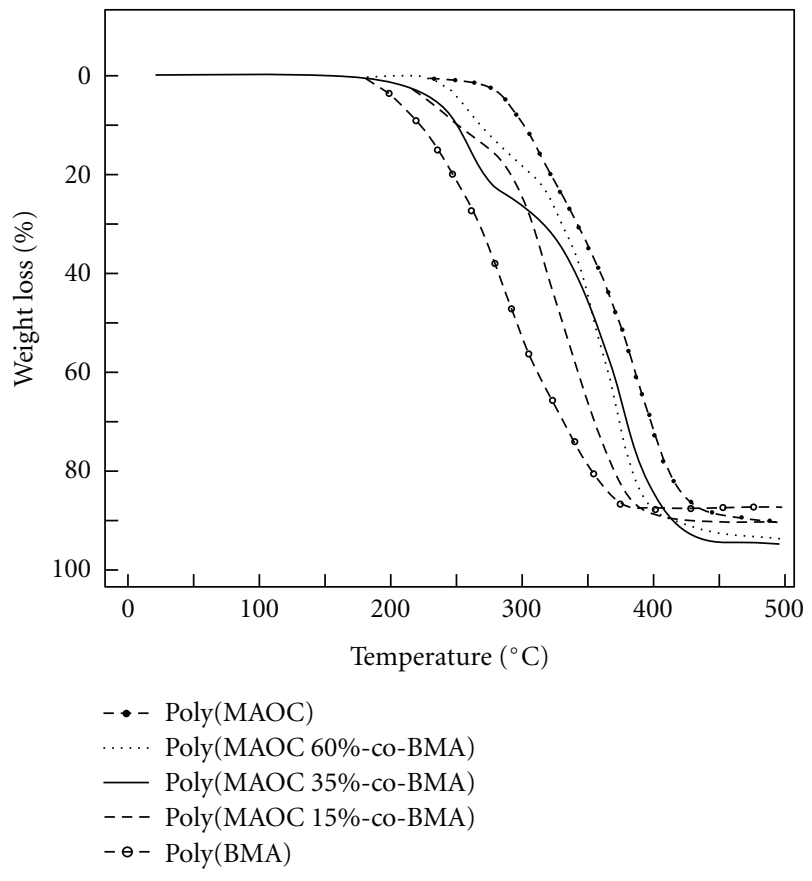

FIgURE 10: TGA curves of homo and copolymers heated under nitrogen at $10^{\circ} \mathrm{C} / \mathrm{min}$ heating rate from room temperature to $500^{\circ} \mathrm{C}$.

from the inflection points on the differential scanning calorimetry (DSC) curves (Figure 6 and Table 1). All the copolymers showed a single transition. $\mathrm{P}(\mathrm{MAOC})$ had a $\mathrm{Tg}$ value higher than those of all the copolymers. This means that two units in copolymer composition form a single phase. The $T g$ of poly(MAOC) synthesized in this study was measured as $146^{\circ} \mathrm{C}$. However, $\mathrm{Tgs}$ of poly(MAOC-coMMA 0,19), poly(MAOC-co-EMA 0,19), poly(MAOC-coIBMA 0,23 ) are 138,112 , and $106^{\circ} \mathrm{C}$, respectively.

The glass transition temperature of MAOC and BMA copolymers prepared by FRP was determined by DSC. The $\mathrm{Tg}$ values of poly(BMA) and poly(MAOC) were found to be $54^{\circ} \mathrm{C}$ and $146^{\circ} \mathrm{C}$, respectively. The $T g$ values obtained for the blends were between $70^{\circ} \mathrm{C}$ and $120^{\circ} \mathrm{C}$ (Figure 7) in accordance with the increasing percentage of PMAOC. The $\mathrm{Tg}$ value of the $76 \mathrm{~mol} \%$ PMAOC copolymer was $117^{\circ} \mathrm{C}$. The high $\mathrm{Tg}$ value of the homopolymer was justified by 


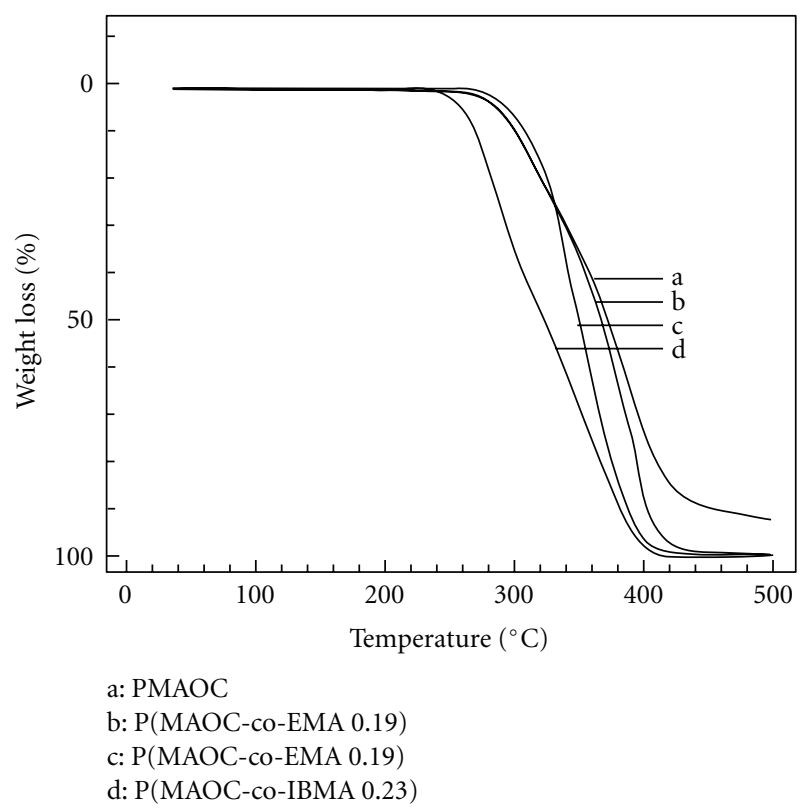

Figure 11: TGA curves of poly(MAOC) and copolymers heated under nitrogen at $10^{\circ} \mathrm{C} / \mathrm{min}$ heating rate from room temperature to $500^{\circ} \mathrm{C}$.

the rigidity of coumarin ring present in the side chains, and mainly by the capability of forming intermolecular dipole-dipole attraction on coumarine with bulk side group. The observed $\mathrm{Tg}$ s of the blend polymers indicate a slightly positive deviation with respect to linearity, which can be associated with a slightly lower free volume than that of a mixture of MAOC and BMA. It is known that an immiscible blend shows glass transition temperature of each individual polymer, but a miscible blend shows only one glass transition temperature. Figure 8 shows DSC curves of poly(MAOC) and poly(BMA) blends. Each polymer blend prepared in this study shows single transition, which can be attributed to poly(MAOC) and poly(BMA) that give the compatible blends. An inner shift of single Tgs for poly(MAOC):poly(BMA) blends indicate good compatibility of both polymers. Plots of the $T g$ values versus mole fractions of PMAOC in the blends are shown in Figure 9. Both the polymers contain polar ester and nonpolar alkyl groups, and they indicate similar kinds of interactions, and also, as was seen in Table 5 their average molecular weights are relatively low. The Tgs by depending on the same composition of copolymer and blend polymers were observed very similar to each other. The $\mathrm{Tg}$ values of the blends and copolymer showed low-positive deviation as illustrated in Figure 9. Since syndiotactic distribution in the homopolymer units is dominant, interchain interactions along the polymer chains in the blend are low because of steric hindrance. This results in increasing of free volume in the blend, and decreasing of their $T g$ values with respect to linearity. The stereoeffects strongly depends on the monomer structures [27]. Therefore, enhancing the stereoeffect may be effective in view of syndiotactic for methacrylates with the relatively bulky side group such as coumarine and phenyl group.
3.5. Thermogravimetric Studies of the Polymers. Thermal studies of the homopolymer and the copolymers were investigated by thermogravimetric measurements. The thermogravimetric curves of poly(MAOC), poly(MAOC-co-MMA $0,19)$, poly(MAOC-co-EMA 0,19), and poly(MAOC-coIBMA 0,23) prepared by FRP are shown in Figure 10. Some thermal degradation characteristics of homo- and copolymers are summarized in Table 5. All the polymers show a thermal degradation with two stages. For the first stage, while the initial decomposition temperature of poly (MAOC) and poly(MAOC-co-MMA 0,19), poly(MAOC-co-EMA 0,19), and poly(MAOC-co-IBMA 0,23) are 270, 267, 268, and $244^{\circ} \mathrm{C}$, respectively. The second stage, that is, $64 \%$ weight loss (with a signal) random chain scission starts at $322^{\circ} \mathrm{C}$ for poly(MAOC), and between 310 and $360^{\circ} \mathrm{C}$ by depending on this kind of the copolymers. Observing higher weight loss in poly(MAOC) is due to mass of coumarin group. The second stage decomposition starts at a lower temperature for poly(IBMA). After $336^{\circ} \mathrm{C}$, thermal stability of poly(MAOCco-MMA 0,19 ) and poly(MAOC-co-MMA 0,19) is increasing. This tendency is also seen at temperatures with $50 \%$ weight loss, for example, $348^{\circ} \mathrm{C}$ for poly(MAOC), 372 and $375^{\circ} \mathrm{C}$ for the poly(MAOC-co-MMA 0,19$)$ and poly(MAOCco-EMA 0,19). All these results show that the thermal stabilities of the polymers decrease to $336^{\circ} \mathrm{C}$ with an presence of alkyl methacrylate units in copolymers. But after $336^{\circ} \mathrm{C}$, it showed that it increased that of the other copolymers except for poly(MAOC-CO-IBMA 0,23).

The thermogravimetric curves for poly(MAOC), poly(BMA), and the three MAOC-BMA copolymers recorded under conditions above mentioned are given in Figure 11 as in comparison with each other. Decomposition temperature of poly(BMA) prepared by FRP occurs in a single step at about $176^{\circ} \mathrm{C}$. On the other hand, poly (MAOC) and MAOC-BMA copolymers prepared by free-radical polymerization shows a two-stage decomposition. For the first stage, while the initial decomposition temperature of poly(MAOC) is $271^{\circ} \mathrm{C}$, in the second stage, that is, $64 \%$ weight loss (with a signal) random chain scission starts at $322^{\circ} \mathrm{C}$ for poly(MAOC). The thermal stabilities of MAOCBMA copolymer systems are considerably different from those of homopolymers. For example, poly(MAOC-co-BMA $0,35)$ shows a decomposition with a two stage. For the first stage, while its initial decomposition temperature is $190^{\circ} \mathrm{C}$, in the second stage, that is, $71 \%$ weight loss random chain scission starts at $302^{\circ} \mathrm{C}$ for poly(MAOC-co-BMA 0,35). Also, the similar behaviors are observed in the other two copolymer systems. Decreasing of initial decomposition temperature of copolymers is due to in BMA units. TGA results of MAOC-BMA copolymer system are summarized in Table 4 as compared with those of poly(BMA)-prepared FRP. The copolymers showed that thermal stability decreased with increasing BMA for copolymer system. A similar tendency for poly(MAOC):poly(BMA) blends is also seen at temperatures with $50 \%$ weight loss, for example, $338^{\circ} \mathrm{C}$ for poly(MAOC 0,15 -co-BMA), $330^{\circ} \mathrm{C}$ for the poly(MAOC)0,15-poly(BMA) blend, and $350^{\circ} \mathrm{C}$ for the 


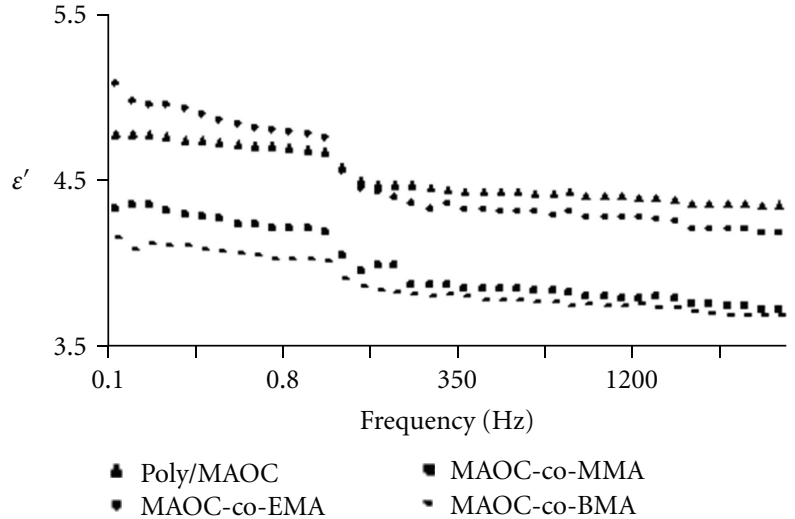

(a)

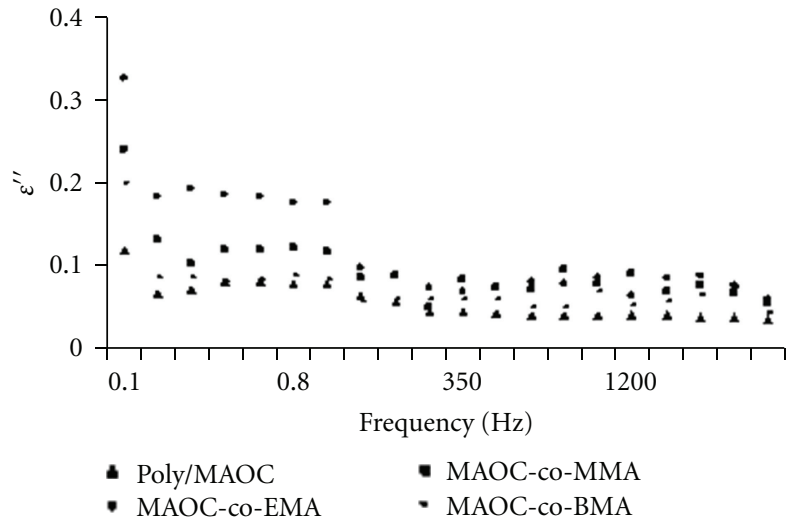

(b)

FIgURE 12: Variation of the dielectric constants (a) and the dielectric loss (b) with frequency for polymers.

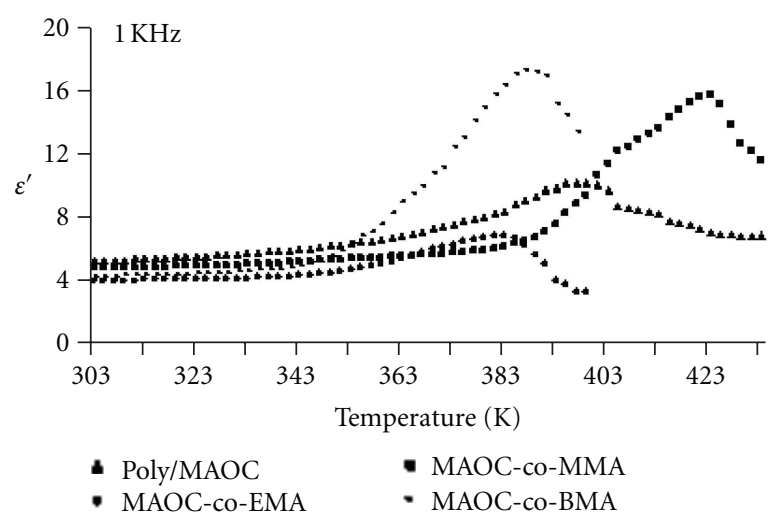

(a)

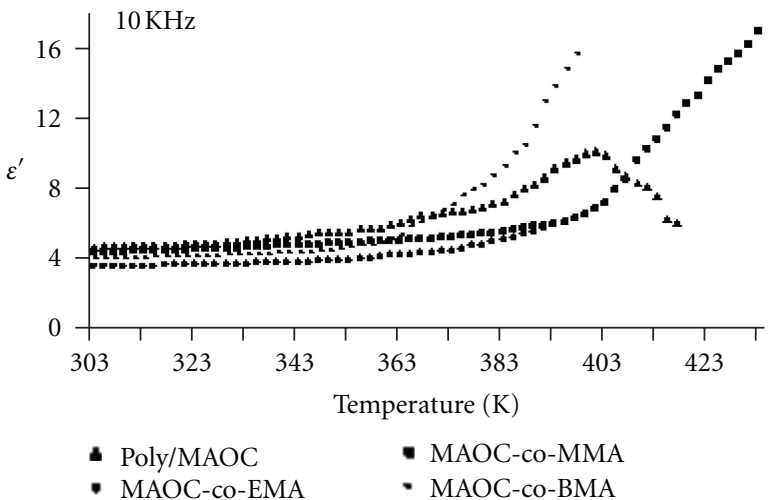

(b)

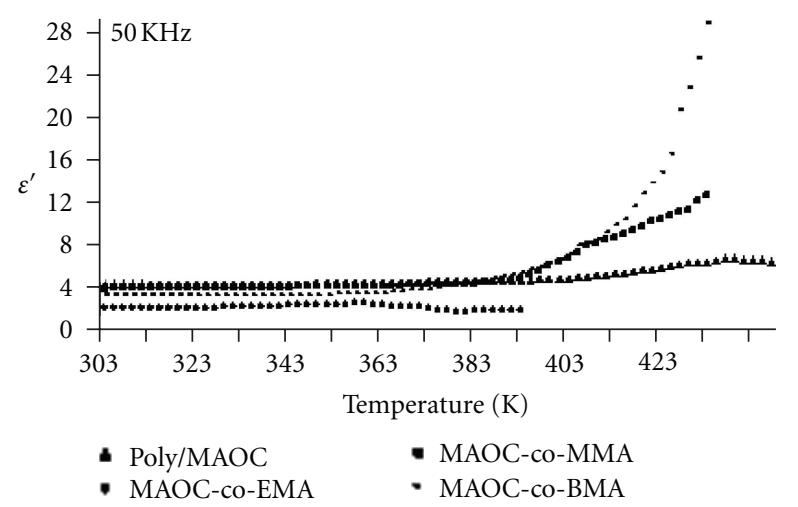

(c)

FIGURE 13: Variation of dielectric constant of polymers with temperature at 1, 10, and $50 \mathrm{KHz}$.

poly(MAOC) 0,35-poly(BMA) blend. All these results show that the thermal stabilities of the polymers decrease with an increase of BMA content in blend or copolymer system.

3.6. Dielectric Measurements. The frequency-dependent measurements of paralel capacitance, $C_{p}$, and dissipation factor, $D f$, were obtained using impedance analyzer for different frequencies in the range $100 \mathrm{~Hz}-2 \mathrm{MHz}$ and am- bient room to $453 \mathrm{~K}$. The dielectric constant $\left(\varepsilon^{\prime}\right)$ and dielectric loss factor $\left(\varepsilon^{\prime \prime}\right)$ were determined as per the following expressions:

$$
\begin{aligned}
& \varepsilon^{\prime}=C_{p} \frac{d}{\varepsilon_{0} A}, \\
& \varepsilon^{\prime \prime}=\varepsilon^{\prime} D f,
\end{aligned}
$$


TABle 4: TGA data for the Polymers.

\begin{tabular}{|c|c|c|c|c|c|}
\hline Polymers & $T_{i}^{\mathrm{a}}\left({ }^{\circ} \mathrm{C}\right)$ & $T_{\% 50}^{\mathrm{b}}\left({ }^{\circ} \mathrm{C}\right)$ & Weight loss $(\%)$ at $350^{\circ} \mathrm{C}$ & Weight loss $(\%)$ at $400^{\circ} \mathrm{C}$ & Residue at $500^{\circ} \mathrm{C}$ \\
\hline Poly(MAOC) & 271 & 371 & 36 & 73 & 8 \\
\hline Poly(MAOC 0,60-co-BMA) & 227 & 357 & 43 & 86 & 6 \\
\hline Poly(MAOC 0,35-co-BMA) & 190 & 360 & 45 & 85 & 5 \\
\hline Poly(MAOC 0,15-co-BMA) & 180 & 330 & 65 & 89 & 10 \\
\hline Poly(BMA) & 176 & 298 & 78 & 87 & 12 \\
\hline Poly(MAOC-co-MMA 0,19) & 268 & 355 & 46 & 97 & 4 \\
\hline Poly(MAOC-co-EMA 0,19) & 269 & 366 & 36 & 83 & 1 \\
\hline Poly(MAOC-co-IBMA 0,23) & 244 & 322 & 66 & 98 & 1 \\
\hline Poly(MAOC) 0,35-poly(BMA) (blend polymer) & 222 & 318 & 75 & 88 & 9 \\
\hline Poly(MAOC) 0,15-poly(BMA) (blend polymer) & 219 & 338 & 65 & 96 & 1 \\
\hline
\end{tabular}

a: initial decomposition temperature of first stage, b: decomposition temperature at $50 \%$ weight loss, c: by mole.

where $C_{p}$ is parallel capacitance, $\varepsilon_{0}$ is permittivity in free space $\left(\varepsilon_{0}=8.854 .10^{-12} \mathrm{~F} / \mathrm{m}\right)$ [28], $d$ is thickness of the polymer sample, and $A$ is surface area of the sample.

The plot of dielectric constant, $\varepsilon^{\prime}$ versus frequency for poly(MAOC), poly(MAOC-co-MMA 0,19), poly(MAOCCo-EMA 0,19), and poly(MAOC-co-IBMA 0,23 ) at various temperatures for constant frequency is shown in Figure 6, respectively. In all the polymers the $\varepsilon^{\prime}$ decreased with increase in frequency and increased with increase in temperature. Overall, the dielectric constant of homo- and copolymers was measured to be in the range $4,75-4,0$ at $1 \mathrm{kHz}$ as was summarized in Table 4 . This tendency in dielectric constant is in agreement with the reported values for similar poly(methacrylate) systems [29-31].

Figure 12 shows the dependence of the dielectric constant on frequence $(1 \mathrm{kHz}-2 \mathrm{MHz})$ for poly(MAOC), poly(MAOC-co-MMA), poly(MAOC-co-EMA), and poly (MAOC-co-IBMA). The dielectric constant $\left(\varepsilon^{\prime}=4,75\right)$ of poly(MAOC) has a value slightly higher according to that of its copolymers. This is probably due to the strong effect of the ester group on molecular polarity. The dielectric constant decreased in case of alkyl groups such as methyl, ethyl, and isobutyl which is next to ester in copolymer. Dielectric constant values of poly(MAOC-co-MMA) $\left(\varepsilon^{\prime}=\right.$ $4,18)$, poly (MAOC-co-EMA) $\left(\varepsilon^{\prime}=4,15\right)$ and poly(MAOCco-IBuMA) $\left(\varepsilon^{\prime}=4,01\right)$. The increase of $\varepsilon^{\prime}$ with increase in temperature is usually associated with the decrease in bond energies [32]. That is, as the temperature increases two effects on the dipolar polarization may occur: (i) it weakens the intermolecular forces and hence enhances the orientational vibration, (ii) it increases the thermal agitation and hence strongly disturbs the orientational vibrations. The dielectric constant becomes larger at lower frequencies and at higher temperatures which is normal in oxide glasses and is not an indication for spontaneous polarization [33]. This may be due to the fact that as the frequency increases, the polarizability contribution from ionic and orientation sources decreases and finally disappears due to the inertia of the ions. Also, this may be due to the tendency of induced
TABLE 5: Dielectric constant, GPC, and DSC data of the polymers.

\begin{tabular}{lccc}
\hline Polymers & $\begin{array}{c}\text { Dielectric constant } \\
\left(\varepsilon^{\prime}\right) \text { at } 1 \mathrm{kHz}\end{array}$ & $\begin{array}{c}\mathrm{Mn}(\mathrm{HI}= \\
\mathrm{Mw} / \mathrm{Mn})\end{array}$ & $\mathrm{Tg}\left({ }^{\circ} \mathrm{C}\right)$ \\
\hline $\begin{array}{l}\text { Poly(MAOC) } \\
\begin{array}{l}\text { Poly(MAOC-co- } \\
\text { MMA0,19) }\end{array}\end{array}$ & 4,75 & $30.700(1,56)$ & 146 \\
$\begin{array}{l}\text { Poly(MAOC-co- } \\
\text { EMA0,19) }\end{array}$ & 4,18 & $20.300(1,68)$ & 138 \\
$\begin{array}{l}\text { Poly(MAOC-co- } \\
\text { IBMA0,23) }\end{array}$ & 4,15 & $32.300(1,69)$ & 112 \\
\hline
\end{tabular}

dipoles in the polymer to orient themselves in the direction of the applied field [34].

In Figure 13, it can also be seen that $\varepsilon^{\prime}$ increases with increase in temperature and at high temperatures it increases more rapidly. This behavior is similar to the polar dielectrics in which the orientation of dipoles is facilitated with rising temperature and thereby the dielectric constant is increased. At low temperatures, the contribution of electronic and ionic components to the total polarizability will be small. As the temperature is increased the electronic and ionic polarizability sources start to increase or the dipoles comparatively become free and they respond to the applied electric field. Thus polarization increases and hence dielectric constant also increases with temperature and as the temperature is increased the electronic and ionic polarizability sources start to increase [35]. These temperatures are values closed to glass transition temperatures of corresponding polymers. Figure 7 shows the variation of dielectric loss factor $\varepsilon^{\prime \prime}$ with temperature at three different frequencies for all the samples. Dielectric loss due to chain motion polymers are more effective at around the glass transition temperature. A result, the compositional dependence of dielectric loss is similar to that of ac conductivity and dielectric constant. 


\section{Conclusion}

Six MAOC-BMA copolymers and copolymers of MAOC with MMA, EMA, and IBMA were prepared by free radical polymerization. ${ }^{1} \mathrm{H},{ }^{13} \mathrm{C} \mathrm{NMR}$, and FTIR techniques revealed the presence of both monomeric units in the copolymer chain. The monomer reactivity ratios for MAOC-BMA system were calculated from the feed composition and copolymer composition determined by ${ }^{1} \mathrm{H}-\mathrm{NMR}$ spectroscopy. The monomer reactivity ratios of MAOC and BMA were computed using Kelen-Tüdös (K-T) and Fineman-Ross (F$\mathrm{R})$ methods and were found to be $r_{1}=0,45, r_{2}=$ 1,$29 ; r_{1}=0.46 ; r_{2}=1,33$, respectively ( $r_{1}$ is monomer reactivity ratio of $\mathrm{MAOC})$. Two monomers have an ideal copolymer tendency because the value of $r_{1} \cdot r_{2}$ is at around 0,58 . In case of poly(MAOC-co-MMA0,19), poly(MAOC-coEMA0,19), and poly(MAOC-co-IBMA 0,23), initial decomposition temperature of copolymers increased with an increase in the molar fraction of MAOC. Thermogravimetric measurements for copolymers of MAOC-BMA showed that thermal decomposition temperature decreased when BMA percentage was increased. On the other hand, the each polymer blend prepared in this study showed single transition, which can be attributed to poly(MAOC) and poly(BMA) to give the compatible blends. An inner shift of single $\mathrm{Tgs}$ for poly(MAOC):poly(BMA) blends indicated good compatibility of both polymers. Dielectric constants of homo- and copolymers were calculated as $100 \mathrm{~Hz}$. It is observed that the dielectric constant decreases sharply up to about $100 \mathrm{~Hz}$ after which it decreases very slowly for all the samples. Dielectric constant and dielectric loss factor increased with temperature.

\section{Acknowledgments}

The authors thank the Firat University Research Fund for financial support of this Project (FÜBAP-1629) and M. Fatih Coşkun for providing GPC chromatograms.

\section{References}

[1] C. Kim, A. Trajkovska, J. U. Wallace, and S. H. Chen, "New insight into photoalignment of liquid crystals on coumarincontaining polymer films," Macromolecules, vol. 39, no. 11, pp. 3817-3823, 2006.

[2] L. Zhao, D. A. Loy, and K. J. Shea, "Photodeformable spherical hybrid nanoparticles," Journal of the American Chemical Society, vol. 128, no. 44, pp. 14250-14251, 2006.

[3] M. P. Brun, L. Bischoff, and C. Garbay, "A very short route to enantiomerically pure coumarin-bearing fluorescent amino acids," Angewandte Chemie-International Edition, vol. 43, no. 26, pp. 3432-3436, 2004.

[4] İ. Erol, G. Sanl, M. Dilek, and L. Özcan, "Synthesis and characterization of novel methacrylate copolymers based on sulfonamide and coumarine: monomer reactivity ratios, biological activity, thermal stability, and optical properties," Journal of Polymer Science Part A, vol. 48, no. 19, pp. 43234334, 2010.

[5] J. Jiang, B. Qi, M. Lepage, and Y. Zhao, "Polymer micelles stabilization on demand through reversible photo-crosslinking," Macromolecules, vol. 40, no. 4, pp. 790-792, 2007.
[6] B. Kiskan and Y. Yagci, "Thermally curable benzoxazine monomer with a photodimerizable coumarin group," Journal of Polymer Science Part A, vol. 45, no. 9, pp. 1670-1676, 2007.

[7] S. R. Trenor, T. E. Long, and B. J. Love, "Photoreversible chain extension of poly(ethylene glycol)," Macromolecular Chemistry and Physics, vol. 205, no. 6, pp. 715-723, 2004.

[8] P. Feng, J. Zhu, Z. Cheng, Z. Zhang, and X. Zhu, "Reversible addition-fragmentation chain transfer polymerization of 7(4-(acryloyloxy)butoxy)coumarin," Polymer, vol. 48, no. 20, pp. 5859-5866, 2007.

[9] J. W. Jeong, Y. Kwon, Y. S. Han, and L. S. Park, "Electroluminescent property and photolithographic process of photosensitive random copolymers," Molecular Crystals and Liquid Crystals, vol. 443, pp. 59-68, 2005.

[10] L. Z. Zhang, Y. Li, Z. X. Liang, Q. S. Yu, and Z. G. Cai, "New crosslinked polymer systems with high and stable optical nonlinearity," Reactive and Functional Polymers, vol. 40, no. 3, pp. 255-262, 1999.

[11] D.-M. Song, K.-H. Jung, J.-H. Moon, and D.-M. Shin, "Photochemistry of chalcone and the application of chalconederivatives in photo-alignment layer of liquid crystal display," Optical Materials, vol. 21, no. 1-3, pp. 667-671, 2003.

[12] Y. Ohe, Ho. Ito, N. Watanabe, and K. Ichimura, "Novel dry photopolymer for volume-phase holograms," Journal of Applied Polymer Science, vol. 77, no. 10, pp. 2189-2200, 2000.

[13] S. R. Trenor, A. R. Shultz, B. J. Love, and T. E. Long, "Coumarins in polymers: from light harvesting to photo-crosslinkable tissue scaffolds," Chemical Reviews, vol. 104, no. 6, pp. 3059-3077, 2004.

[14] B. D. Wagner, "The use of coumarins as environmentallysensitive fluorescent probes of heterogeneous inclusion systems," Molecules, vol. 14, pp. 210-237, 2009.

[15] K. Liangs, M. Dossi, D. Moscatelli, and R. A. Hutchinson, "An investigation of free-radical copolymerization propagation kinetics of styrene and 2-hydroxyethyl methacrylate," Macromolecules, vol. 42, no. 20, pp. 7736-7744, 2009.

[16] K. Rajendrakumar and R. Dhamodharan, "Ambient temperature atom transfer radical copolymerization of tetrahydrofurfuryl methacrylate and methyl methacrylate: reactivity ratio determination," European Polymer Journal, vol. 45, no. 9, pp. 2685-2694, 2009.

[17] M. L. Houchin and E. M. Topp, "Physical properties of PLGA films during polymer degradation," Journal of Applied Polymer Science, vol. 114, no. 5, pp. 2848-2854, 2009.

[18] K. Demirelli, K. Esin, and M. Coşkun, "Polymers based on phenyl methacrylate: synthesis via atom transfer radical polymerization, characterization, monomer reactivity ratios, and thermal stabilities," Journal of Applied Polymer Science, vol. 99, no. 6, pp. 3344-3354, 2006.

[19] R. Popielarz, C. K. Chiang, R. Nozaki, and J. Obrzut, "Dielectric properties of polymer/ferroelectric ceramic composites from $100 \mathrm{~Hz}$ to $10 \mathrm{GHz}$," Macromolecules, vol. 34, no. 17, pp. 5910-5915, 2001.

[20] G. Q. Chen, Z. Q. Wu, J. R. Wu, Z. C. Li, and F. M. $\mathrm{Li}$, "Synthesis of alternating copolymers of N-substituted maleimides with styrene via atom transfer radical polymerization," Macromolecules, vol. 33, no. 2, pp. 232-234, 2000.

[21] H. Shinoda, P. J. Miller, and K. Matyjaszewski, "Improving the structural control of graft copolymers by combining ATRP with the macromonomer method," Macromolecules, vol. 34, no. 10, pp. 3186-3194, 2001.

[22] L. H. Yee, J. P. A. Heuts, and T. P. Davis, "Copolymerization propagation kinetics of dimethyl itaconate and styrene: strong 
entropic contributions to the penultimate unit effect," Macromolecules, vol. 34, no. 11, pp. 3581-3586, 2001.

[23] F. Tüdös and T. Kelen, "T.Analysis of linear methods for determining copolymerization reactivity ratios, 1.New Improved Linear Graphic Method," Journal of Macromolecular Science. Chemistry A, vol. 9, no. 1, pp. 1-27, 1975.

[24] M. R. Aguilar, A. Gallardo, M. Del Mar Fernández, and J. San Román, "In situ quantitative," Macromolecules, vol. 35, no. 6, pp. 2036-2041, 2002.

[25] C. J. Hawker, A. W. Bosman, and E. Harth, "New polymer synthesis by nitroxide mediated living radical polymerizations," Chemical Reviews, vol. 101, no. 12, pp. 3661-3688, 2001.

[26] C. Elvira, A. Gallardo, and J. San Román, "Free radical copolymerization of methyl methacrylate with methacrylic monomers derived from salicylic acid: microstructural analysis, chain flexibility and hydration behaviour of the prepared copolymers," Polymer, vol. 40, no. 25, pp. 6911-6924, 1999.

[27] W. Liu, K. Tang, Y. Guo, Y. Koike, and Y. Okamoto, "Tacticity control in the radical polymerization of 2,2,2-trifluoroethyl methacrylate with fluoroalcohol," Journal of Fluorine Chemistry, vol. 123, no. 1, pp. 147-151, 2003.

[28] D. Štefanec and P. Krajnc, "4-vinylbenzyl chloride based porous spherical polymer supports derived from water-in-oilin-water emulsions," Reactive and Functional Polymers, vol. 65, no. 1-2, pp. 37-45, 2005.

[29] P. Seven, M. Coşkun, and K. Demirelli, "Synthesis and characterization of two-armed graft copolymers prepared with acrylate and methacrylate using atom transfer radical polymerization," Reactive and Functional Polymers, vol. 68, no. 5, pp. 922-930, 2008.

[30] C. C. Ku and R. Liepins, Electrical Properties of Polymers, Hanser Publishers, Munich, Germany, 1987.

[31] K. P. Singh and P. N. Gupta, "Study of dielectric relaxation in polymer electrolytes," European Polymer Journal, vol. 34, no. 7, pp. 1023-1029, 1998.

[32] A. A. Bahgat and Y. M. Abou-Zeid, "Mixed alkali effect in the K," Physics and Chemistry of Glasses, vol. 42, no. 6, pp. 361370, 2001.

[33] M. Prashant Kumar, T. Sankarappa, B. Vijaya Kumar, and N. Nagaraja, "Dielectric relaxation studies in transition metal ions doped tellurite glasses," Solid State Sciences, vol. 11, no. 1, pp. 214-218, 2009.

[34] M. Akram, A. Javed, and T. Z. Rizv1, "Dielectric properties of industrial polymer composite materials," Turkish Journal of Physics, vol. 29, no. 6, article 124, pp. 355-362, 2005.

[35] M. H. Shaaban, A. A. Ali, and M. K. El-Nimr, "The AC conductivity of tellurite glasses doped with $\mathrm{Ho}_{2} \mathrm{O}_{3}$," Materials Chemistry and Physics, vol. 96, no. 2-3, pp. 433-438, 2006.

[36] M. Fineman and S. Ross, Journal of Polymer Science-Polymer Chemistry Edition, vol. 9, no. 1, 1975. 

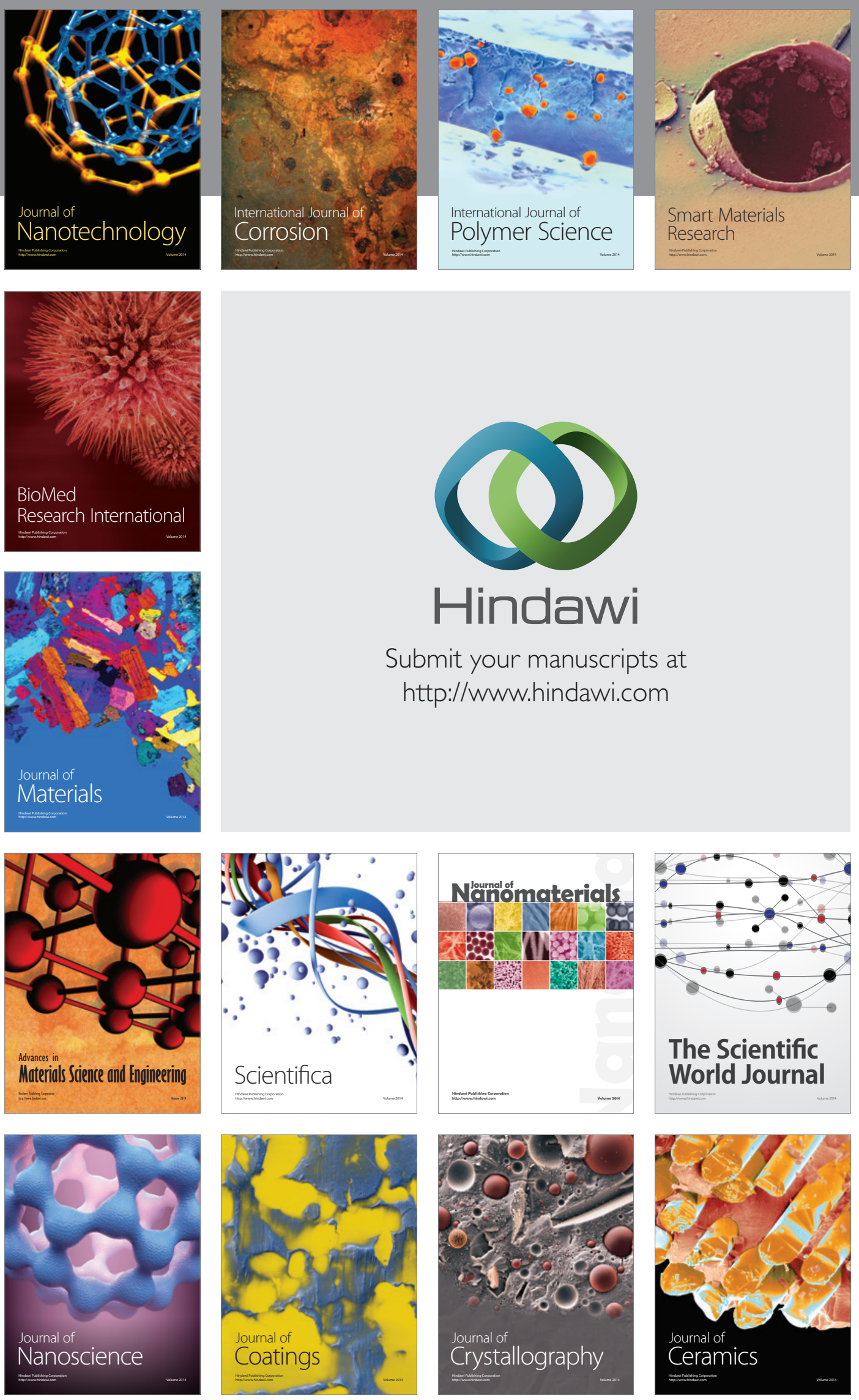

The Scientific World Journal

Submit your manuscripts at

http://www.hindawi.com

\section{World Journal}

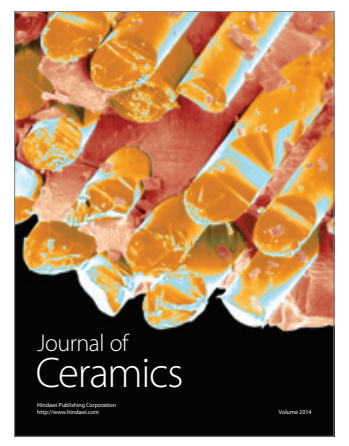

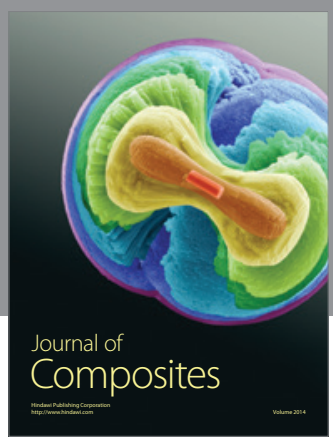
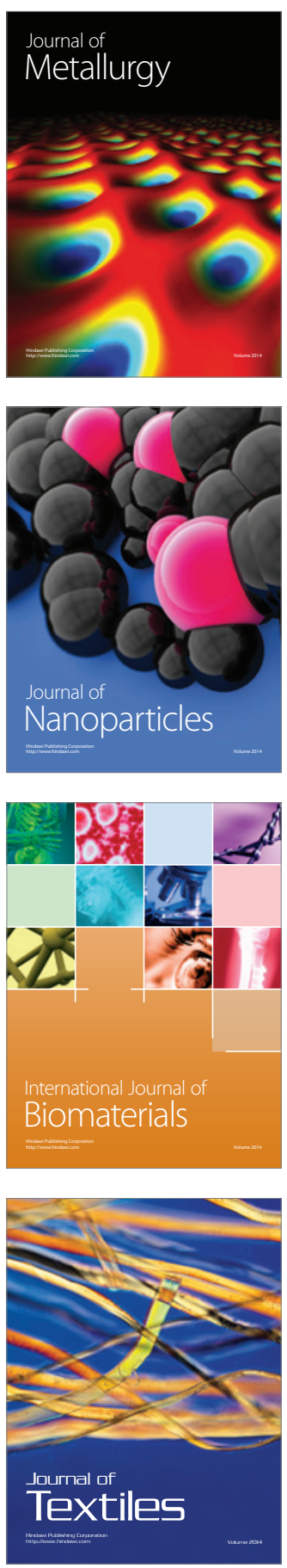